\title{
Literature Review Filantropi Islam antara Tahun 2008 hingga 2018
}

\section{A Review on Islamic Philanthropy Literatures between 2008 to 2018}

\author{
Aris Puji Purwatiningsih ${ }^{1}$, Muchlis Yahya ${ }^{2}$ \\ ${ }^{1}$ UIN Walisongo Semarang, Jl. Walisongo No. 3-5, Tambakaji, Ngaliyan, Kota Semarang, Jawa Tengah 50185, \\ email: aris.puji.p@gmail.com \\ ${ }^{2}$ UIN Walisongo Semarang, Jl. Walisongo No. 3-5, Tambakaji, Ngaliyan, Kota Semarang, Jawa Tengah 50185, \\ email: muchlisyahya@walisongo.ac.id
}

\begin{abstract}
The author is interested in reviewing Islamic philanthropic literature between 2008 and 2018 because Islamic philanthropic behavior is found in any community, from the scope of the poorest countries to even the developed world. In addition, Islamic philanthropy is an object of study that has been widely studied in the social and economic fields. Articles about Islamic philanthropy were obtained using the zakat keyword on Emerald Insight between 2008 and 2018. The search results of 37 articles were then grouped into six topics discussing management, CSR, philanthropy, poverty, charity, religion, distribution, and collection. The findings show that Islamic philanthropy is a topic that is widely discussed by economists and researchers both muslim and non muslim. This is because Islamic philanthropy is the most realistic way to reduce poverty and social inequality today. However, the lack of optimal management of potential Islamic philanthropic funds has hampered the achievement of this goal.
\end{abstract}

Keywords: Infaq, Islamic philanthropy, poverty, zakah

\begin{abstract}
Abstrak. Penulis tertarik mengulas literatur filantropi Islam antara tahun 2008 hingga 2018 karena perilaku filantropi Islam dijumpai di lingkungan masyarakat manapun, dari lingkup masyarakat negara paling miskin hingga lingkup masyarakat negara maju sekalipun. Selain itu, filantropi Islam merupakan obyek kajian yang telah banyak diteliti dalam bidang sosial dan ekonomi. Artikel-artikel seputar filantropi Islam didapat dengan menggunakan kata kunci zakat pada Emerald Insight antara tahun 2008 sampai 2018. Hasil pencarian sebanyak 37 artikel kemudian dikelompokkan menjadi enam topik pembahasan seputar manajemen, CSR, filantropi, kemiskinan zakat, agama, distribusi, dan penghimpunan. Temuan menunjukkan bahwa filantropi Islam menjadi topik yang banyak dibahas oleh ekonom dan peneliti muslim maupun non muslim. Hal ini karena filantropi Islam merupakan cara paling realistis untuk mengurangi angka kemiskinan dan kesenjangan sosial masyarakat saat ini. Namun kurang optimalnya manajemen pengelolaan potensi dana filantropi Islam menghambat pencapaian tujuan tersebut.
\end{abstract}

Kata kunci: Filantropi Islam, infak, kemiskinan, zakat

\section{PENDAHULUAN}

Kesejahteraan manusia bisa diwujudkan jika kebutuhan manusia yang berupa sandang, pangan, perumahan, dan kesehatan bisa terpenuhi. Namun tidak semua manusia mampu memenuhi kebutuhan hidup mereka tanpa bantuan orang lain yang disebabkan kurangnya akses dan tidak adanya kesempatan untuk mendapatkan pekerjaan yang layak untuk kehidupannya. Hal ini yang menjadi penyebab dorongan praktik perilaku membantu orang lain yang saat ini dikenal sebagai filantropi.

Istilah filantropi Islam dalam QS Al Kahfi (18):30 bisa diartikan sebagai bentuk kebaikan hakiki (albirr) yang merupakan perwujudan fundamental keimanan. Kebaikan hakiki merupakan perwujudan iman yang benar dan ketaatan kepada Allah yang diwujudkan dalam bentuk kasih sayang kepada sesama manusia. Qardawi (1973) menyatakan bahwa bentuk kasih sayang kepada sesama manusia bisa diwujudkan dalam perbuatan derma/memberi, yang dalam Islam dikenal sebagai pemberian wajib (zakat) dan pemberian sukarela (sedekah, infak, wakaf, hadiah). Zakat dikategorikan sebagai filantropi Islam berdasarkan penelitian Fauzia (2008), Beik dan Arsyianti (2016), Muhammad dan Saad (2016), serta John dan Shireen (2005). 
Kajian seputar filantropi Islam (zakat, infak, sedekah, wakaf, dan hadiah) penting dilakukan karena perilaku memberi/derma ditemukan di lingkup masyarakat negara paling miskin hingga lingkup masyarakat negara welfare state sekalipun (Roelofs, 2007). Selain itu, praktik filantropi juga sudah dijumpai dalam tradisi Islam pada masa Rasulullah sebagai alat untuk mewujudkan keadilan sosial, menghilangkan penindasan ekonomi, dan meningkatkan kesejahteraan masyarakat (Ismail, 2014).

Potensi dana filantropi masyarakat Islam di dunia adalah sekitar US\$250 milyar sampai US\$1 triliun, meskipun demikian tantangan terbesar adalah bagaimana memobilisasi dan mengelola sumber dana ini agar bisa optimal pencapiannya (Alam, 2010). Menurut Ketua BAZNAS Bambang Sudibyo, potensi zakat Indonesia berdasarkan PDB tahun 2010 adalah Rp217 triliun dan meningkat menjadi Rp 286 triliun pada tahun 2015. Namun realisasi penghimpunan masih rendah, yaitu Rp3.7 triliun pada tahun 2015 (BAZNAS, 2017). Pencapaian filantropi Islam di negara-negara dengan mayoritas penduduk beragama Islam juga belum mampu secara optimal mengentaskan kemiskinan dan mengurangi kesenjangan sosial. Hal ini memerlukan kajian yang lebih mendalam agar potensi dana filantropi Islam di dunia dan di Indonesia khususnya bisa lebih optimal sehingga kemiskinan dan kesenjangan sosial bisa dikurangi.

\section{TINJAUAN PUSTAKA}

Istilah filantropi Islam dalam QS Al Kahfi (18):30 bisa diartikan sebagai bentuk kebaikan hakiki (albirr) yang merupakan perwujudan fundamental keimanan. Kebaikan hakiki merupakan perwujudan iman yang benar dan ketaatan kepada Allah yang diwujudkan dalam bentuk kasih sayang kepada sesama manusia. Dalam Qardawi (1973), bentuk kasih sayang kepada sesama manusia bisa diwujudkan dalam perbuatan derma/memberi, yang dalam Islam dikenal sebagai pemberian wajib (zakat) dan pemberian sukarela (sedekah, infak, wakaf, hadiah). Semua amal perbuatan seorang muslim merupakan buah dari ilmu, akal, dan berakar pada keesaan Tuhan harus didasari nilai-nilai keimanan, termasuk perbuatan derma atau memberi yang dikenal sebagai filantropi. Seorang muslim melakukan derma juga merupakan buah dari nilai-nilai keimanan yang sudah menyatu dengan kepribadian (Mehmet, 1997). Hal ini yang menyebabkan zakat termasuk derma yang merupakan buah keimanan yang tidak bisa dipisahkan dengan rasa kasih sayang yang dimiliki manusia. Zakat sebagai bentuk cinta manusia juga dinyatakan Dehuji (2016). Selain zakat, Islam juga mengenal bentuk lain dari filantropi sebagai bentuk filantropi dalam Islam derma yang digolongkan sebagai infak, sedekah, dan wakaf (Fauzia, 2008).

Filantropi Islam memiliki peran penting dalam perekonomian karena merupakan instrumen pengalihan pendapatan orang kaya kepada orang miskin melalui zakat, infak, dan sedekah (Sumadi, 2007). Selain membantu meningkatkan kesejahteraan secara material, zakat juga bisa berdampak positif terhadap peningkatan spiritualitas ashnaf zakat (Beik \& Arsyianti, 2016). Konsep kedermawanan dalam agama Islam yang berupa zakat, infak, sedekah, dan wakaf bisa digunakan sebagai jalan keluar permasalahan dalam bidang ekonomi dan sosial (IISEP et al., 2007).

Bentuk filantropi Islam yang pertama adalah zakat. Zakat adalah rukun Islam keempat yang wajib dikerjakan oleh semua orang Islam mukallaf yang hartanya sudah mencapai batas nishab dan haul. Perintah zakat dalam Al Quran sering disandingkan dengan perintah mengerjakan shalat, misalnya dalam (QS Al Baqarah (2):43) yang artinya: "dan dirikanlah shalat, tunaikanlah zakat, dan rukuklah beserta orang yang rukuk." Contoh yang lain ada pada QS Al Maidah (5):55 yang artinya "Sesungguhnya penolong kamu hanyalah Allah, Rasul-Nya, dan orang-orang yang beriman. Perhatian Islam terhadap zakat bisa dilihat dalam penyebutan kata zakat yang bersamaan dengan kata shalat disebut sebanyak 82 kali dalam Al Quran" (Anshori, 2018). Dimensi-dimensi kebajikan yang luas dalam zakat, infak, dan sedekah merupakan istilah-istilah yang menunjukkan bentuk-bentuk resmi filantropi Islam (Abubakar \& Barmualim, 2006).

Perintah shalat yang diikuti dengan zakat mengindikasikan bahwa manusia selain memiliki kewajiban kepada Allah juga memiliki tanggung jawab terhadap manusia (makhluk pribadi dan makhluk sosial). 
Makhluk pribadi yang dituntut kewajiban beribadah kepada Tuhan dan makhluk sosial yang juga dituntut memiliki kepedulian terhadap lingkungannya. Selain itu, adanya perintah zakat yang mengikuti perintah shalat bisa diartikan juga bahwa zakat tidak kalah penting pelaksanaannya daripada shalat. Zakat menurut bahasa adalah suci dan tumbuh, sedangkan menurut syara' adalah mengeluarkan sebagian harta karena perintah Allah yang wajib hukumnya (Az-Zuhaili, 1985).

Potensi zakat pada dekade terakhir menjadi harapan baru bagi masyarakat berpenghasilan rendah agar bisa keluar dari garis kemiskinan (Mustaqim \& Al-Banna, 2015). Filantropi merupakan perbuatan yang pasti ada dalam Islam karena terdapat perintah berzakat dalam Islam. Manajemen yang buruk dalam pengelolannya membuat kepercayaan masyarakat berkurang (Bremer, 2004). Namun secara umum, praktik filantropi Islam dilakukan secara tradisional yang berupa pemberian langsung untuk kebutuhan konsumsi, tanpa mempertimbangkan pemberdayaan jangka panjangnya (Hasan, 2015).

Bentuk filantropi Islam yang kedua adalah sedekah dan infak. Sedekah adalah pemberian yang diniatkan untuk mendekatkan diri kepada Allah dengan barang yang dibutuhkan (Al-Qahtani, 2003.). Sedekah dalam bahasa yang dikenal masyarakat luas adalah segala macam bentuk pemberian materi yang pemanfaatannya bisa mendatangkan kemudahan. Masyarakat lebih mudah memahami sedekah dalam bentuk materi atau barang. Sedekah adalah pemberian yang bersifat sukarela yang tidak diwajibkan Allah (Al-Qohthāni, 1426H). Ulama fiqih membedakan infak dan sedekah dari segi waktu pelaksanaannya. Infak dilakukan pada saat mendapatkan rizki yang diartikan sebagai kelebihan harta, sedang sedekah dilakukan kapan saja, dan infak merupakan bagian dari sedekah (Hanafi, 2005). Infak juga memiliki arti yang luas dalam Al Quran dan hadis. Dalam QS Al Furqan (25):67 yang artinya: "Dan orang- orang yang apabila membelanjakan (harta), mereka tidak berlebihan, dan tidak (pula) kikir, dan adalah (pembelanjaan itu) di tengah- tengah antara yang demikian".

Bentuk filantropi Islam yang ketiga adalah wakaf. Wakaf adalah salah satu bentuk filantropi (kemurahan hati) yang bisa menjadi alternatif pengentasan kemiskinan di negara-negara muslim (Arif, 2010). Keberadaan wakaf sebagai institusi Islam telah ada sejak masa Rasulullah SAW sebagai pendorong dan penggerak ekonomi Islam (Ismail et al., 2015). Selain itu, praktik wakaf produktif berupa uang sudah dicontohkan Khalifah Umar ibn al-Khattāb ketika menjadikan tanah di Khaibar sebagai lahan produktif untuk kepentingan Umat Islam (Suryani \& Isra, 2016). Pengertian wakaf menurut jumhur (mayoritas ulama) adalah menahan harta dan mengelola harta yang diwakafkan di jalan Allah tanpa campur tangan pemberi wakaf (Az-Zuhaili, 1985). Wakaf berupa uang tunai juga bisa menjadi salah satu solusi dalam pembiayaan barang-barang publik dan mixed public goods. Praktik wakaf tunai sudah dicontohkan oleh Khalifah Utsman bin Affan dengan membeli sumur milik penduduk Madinah agar bisa digunakan bersama oleh masyarakat luas pada waktu itu. Menurut jumhur, dasar hukum hadis wakaf adalah hadis dari Ibnu Umar ketika Rasulullah mendapatkan tanah di Khaibar dan memerintahkan Umar agar tanah tersebut dimanfaatkan hasilnya untuk disedekahkan dan melarang tanah tersebut dijual, dihibahkan, dan diwariskan. (As-Syaukani, 1961).

Bentuk filantropi Islam berikutnya adalah hibah/hadiah. Hibah/hadiah juga bisa diartikan sebagai tabarru' sebagaimana diartikan dalam QS Al Maidah (5):2 yang artinya, "maka tolong-menolonglah kalian dalam kebaikan dan takwa" (Ali, 2015). Hadiah adalah pemberian kepada orang lain dengan niat ibadah. Hibah merupakan nama lain dari hadiah dan sedekah (Az-Zuhaili, 1985).

Tujuan praktik filantropi Islam dalam bentuk zakat, infak, sedekah, wakaf, dan hadiah adalah mewujudkan kesejahteraan masyarakat dan mengurangi kemiskinan. Kemiskinan adalah masalah serius yang harus segera ditangani, karena akan mendorong permasalahan-permasalahan lain dalam bidang sosial, ekonomi, dan politik. Kemiskinan menurut BPS adalah kondisi ketidakmampuan ekonomi yang menyebabkan seseorang tidak mampu memenuhi kebutuhan dasar kehidupan (BPS, 2018). Kasim (2006) membagi penyebab kemiskinan menjadi dua. Pertama, faktor alamiah yang berupa kondisi lingkungan yang miskin, kurangnya ilmu pengetahuan, bencana alam, dan lain-lain. Kedua, faktor non alamiah yang berupa kesalahan kebijakan ekonomi, praktik korupsi, ketidakstabilan kondisi politik, salah urus sumber daya alam, dan lainnya. Penyebab utama 
kemiskinan di Indonesia adalah faktor non alamiah yang berupa kesalahan dalam kebijakan ekonomi (Kasim, 2006). Hal ini sesuai dengan pendapat Chapra (1992) bahwa kemiskinan dalam Islam lebih disebabkan oleh faktor sosio-kultural sehingga dibutuhkan tanggung jawab sosial masyarakat secara keseluruhan untuk mengatasinya.

Chapra (1992) juga menyebutkan bahwa Keynesian sebenarnya belum berhasil memecahkan masalah kemiskinan, pengangguran, inflasi, kesenjangan sosial. Sejarah Islam pernah memiliki catatan terbaik dalam pengentasan kemiskinan pada masa Khalifah Umar bin Abdul Aziz (Ash-Shalabi, 2014). Pada masa itu, baitul maal sebagai lembaga pengelola semua dana filantropi Islam saat itu berhasil mengentaskan 100 persen angka kemiskinan. Hal ini dibuktikan dengan sulitnya baitul maal mencari mustahik pada masa itu. Indonesia melalui kebijakan pemerintah pusat dan pemerintah daerah telah mengambil beberapa kebijakan penanggulangan kemiskinan, yaitu beras miskin (raskin), jaminan kesehatan masyarakat (jamkesmas), PNPM (Program Pemberdayaan Masyarakat Mandiri) pedesaan dan perkotaan, bedah rumah, dan bantuan khusus kemiskinan (Bhinadi, 2017).

\section{METODE}

Studi ini menggunakan analisis deskriptif dengan berdasarkan data seputar isu zakat dan filantropi Islam pada Emerald Insight berupa makalah seminar, jurnal, dan artikel dalam kurun waktu 2008 hingga 2018 dengan menggunakan kata kunci zakat. Hasil penelusuran menemukan sebanyak 37 artikel yang kemudian dianalisis sesuai kecenderungan fokus pembahasan artikel pada abstrak. Berdasarkan fokus artikel yang diketahui melalui abstrak, artikel yang ditemukan dikelompokkan menggunakan empat kata kunci dalam Bahasa Inggris dan Bahasa Indonesia, yaitu manajemen zakat yang meliputi pengumpulan dan pendistribusian zakat, filantropi, BAZNAS, dan CSR. Setiap kelompok artikel kemudian akan dianalisis menggunakan analisis deskriptif.

Pada beberapa penelitian mungkin akan terlihat tumpang tindih dalam hal sifat dan minat penelitian pada abstraknya. Telaah artikel akan dibuat berdasarkan kriteria intensitas penyebutan kata kunci tentang manajemen zakat, pengumpulan dan pendistribusian zakat, filantropi, BAZNAS, dan CSR. Hasil penelitian ini mencoba memberikan informasi seputar isu-isu zakat dan filantropi agar bisa bermanfaat untuk perkembangan filantropi Islam dalam dunia pendidikan, penelitian, dan lembaga yang fokus terhadap isu zakat dan filantropi untuk mendapatkan solusi dalam masalah ini.

\section{PEMBAHASAN}

\section{Jumlah Artikel Berdasarkan Tahun}

Sepanjang tahun 2008 sampai 2018, terdapat 37 artikel yang membahas filantropi Islam pada Emerald Insight. Jumlah artikel terbanyak ada pada tahun 2017, yaitu sebanyak 11 artikel. Pada tahun 2013 sebanyak lima artikel, kemudian pada tahun 2014 sebanyak empat artikel. Jumlah artikel lainnya kurang dari empat artikel tiap tahunnya. Jumlah artikel yang membahas filantropi Islam di EmeraldInsight dapat dilihat pada Tabel 1.

Tabel 1 Jumlah artikel filantropi Islam di EmeraldInsight pada tahun 2008-2018

\begin{tabular}{cccccccccccc}
\hline Tahun & 2008 & 2009 & 2010 & 2011 & 2012 & 2013 & 2014 & 2015 & 2016 & 2017 & 2018 \\
\hline Jumlah & 1 & 2 & 2 & 3 & 1 & 5 & 4 & 3 & 3 & 11 & 2 \\
\hline
\end{tabular}

\section{Fokus Artikel}

Fokus artikel terbanyak adalah tentang manajemen zakat sebanyak 16 artikel, kemudian CSR tujuh artikel, kemiskinan dan zakat masing-masing tiga artikel. Jumlah artikel berdasarkan fokus bahasannya dapat dilihat pada Tabel 2 . 
Manajemen menjadi fokus artikel terbanyak karena fokus artikel yang paling banyak dibicarakan seputar zakat adalah tentang manajemen zakat. Manajemen zakat meliputi proses pengumpulan, pengorganisasian, dan pendistribusian zakat. Menurut laporan Bank Dunia (World Bank) pada tahun 2010, manajemen zakat menjadi sangat menarik untuk selalu dibahas karena potensi zakat di dunia yang begitu besar yang mencapai sebesar US\$139.32 milyar per tahun, namun data menunjukkan sekitar 3 milyar orang hidup dalam kemiskinan. Tiga puluh lima (35) persen dari jumlah tersebut berasal dari negara-negara Islam.

Tabel 2 Jumlah artikel berdasarkan fokus bahasan

\begin{tabular}{cc}
\hline Fokus Artikel & Jumlah \\
\hline Manajemen & 16 \\
CSR & 7 \\
Filantropi & 5 \\
Kemiskinan & 3 \\
Zakat & 3 \\
Agama & 1 \\
Distribusi & 1 \\
Penghimpunan & 1 \\
\hline Total & 37 \\
\hline
\end{tabular}

Fokus artikel terbanyak kedua adalah tentang Corporate Social Responsibility (CSR). Menurut Andreoni (2001), Corporate Social Responsibility (CSR) merupakan lembaga yang sering dikenal masyarakat untuk melakukan filantropi. Namun kehadiran CSR yang ingin memberikan pencerahan tentang hak asasi manusia kadang mendapat pertentangan dari masyarakat karena kultur paternalistik mengakar di masyarakat (Josep et al., 2011). Hal ini sering terjadi pada masyarakat Afrika yang memiliki kultur paternalistik yang menganggap kedudukan laki-laki lebih tinggi daripada perempuan.

Pembahasan seputar filantropi menempati urutan ketiga karena perilaku filantropi dijumpai di manamana sehingga mendorong tumbuhnya berbagai lembaga amal, namun keputusan donor memilih satu lembaga ini sangat dipengaruhi sejarah dan faktor budaya lembaga amal tersebut (CERPhi, 2018). Penyebab kedua karena tidak semua manusia mampu memenuhi kebutuhan hidup mereka tanpa bantuan orang lain. Filantropi sebagai perilaku membantu orang lain telah dipraktikkan sejak masa Rasulullah sebagai alat mewujudkan keadilan sosial dan menghilangkan penindasan ekonomi (Ismail $\&$ Ghafar, 2013). Perilaku filantropi selalu dijumpai di lingkungan masyarakat manapun, dari lingkup masyarakat negara paling miskin hingga lingkup masyarakat di negara maju sekalipun (Roelofs, 2007).

Potensi dana filantropi masyarakat Islam di dunia adalah sekitar US\$ 250 milyar sampai US\$ 1 triliun, meskipun demikian tantangan terbesar adalah bagaimana memobilisasi dan mengelola sumber dana ini agar bisa optimal pencapiannya (Alam, 2010). Potensi zakat pada dekade terakhir bisa menjadi harapan baru bagi masyarakat berpenghasilan rendah agar bisa keluar dari garis kemiskinan. Praktik filantropi Islam dalam bentuk zakat penghasilan dan sedekah di Nigeria sebenarnya bisa mengurangi angka kemiskinan jika dikelola dengan optimal. Selain mengurangi angka kemiskinan, juga bisa mendukung pencapaian pendidikan dasar, mengurangi kelaparan, mempromosikan kesetaraan gender, dan meningkatkan pemberdayaan perempuan (Raimi et al., 2010). Dalam bidang kesehatan, potensi dana zakat penghasilan dan sedekah di Nigeria juga bisa digunakan untuk mengurangi angka kematian anak, meningkatkan kesehatan ibu, membantu korban perang, membantu penanganan HIV, malaria, dan penyakit lainnya. Dalam bidang lingkungan hidup, dana zakat penghasilan dan sedekah juga bisa digunakan untuk meningkatkan kelestarian lingkungan dan kemitraan global dalam pembangunan. 
Agar potensi penghimpunan dana filantropi Islam bisa optimal, lembaga filantropi harus mengetahui karakteristik donor. Karakter donor sangat berhubungan dengan demografi, sosial ekonomi, psikografis, serta motivasi donor dan calon donor (Kasri, 2013). Oleh karena itu lembaga filantropi Islam harus bisa membaca dan menganalisis faktor-faktor tersebut agar bisa menemukan strategi yang paling tepat dalam branding pada pasar yang tersedia. Hal ini bertujuan agar penghimpunan dan distribusi dana filantropi Islam bisa optimal dan memberi kepuasan kepada donor. Metode efisiensi dan efektivitas pengelolaan zakat mutlak diperlukan agar zakat bisa optimal dalam meningkatkan kesejahteraan masyarakat. Hal ini sesuai dengan pernyataan Hasan (2014) bahwa keuangan mikro Islam di Pulau Andaman, Thailand terbukti bisa membantu meningkatkan perekonomian masyarakat dan membantu pengelolaan sumber daya lokal yang ada ketika dikelola dengan efektif dan efisien.

Keuangan mikro juga bisa digunakan untuk mengurangi angka kemiskinan di Yogyakarta, Indonesia. Adnan dan Ajija (2015) juga menyebutkan bahwa adanya BMT (baitul maal wa tamwil) di Yogyakarta terbukti bisa mengurangi kemiskinan anggota BMT. Sebaliknya dengan berkurangnya kemiskinan anggota BMT, omzet dan keuntungan BMT juga semakin meningkat. Hal ini yang disebut keberkahan dalam Islam yang diartikan sebagai ziyadatulhoir (bertambahnya kebaikan). Selain kegiatan penghimpunan zakat, distribusi zakat juga harus mendapat perhatian serius agar bisa memberdayakan masyarakat. Kegiatan pemberdayaan masyarakat dalam bidang kewirausahaan sangat tepat dalam pemberdayaan mustahik di Selangor, Malaysia (Yusuf \& Derus, 2013). Hal ini disebabkan karena kewirausahaan termasuk seni dan pola pikir. Seni dalam merancang suatu bisnis dengan pengetahuan yang dimiliki untuk meminimalisir kegagalan dalam bisnis. Pola pikir wirausaha adalah kreatif dan inovatif dengan sumber daya yang tersedia. Dengan gaya bisnis dan pola pikir ini diharapkan seorang mustahik akan berubah menjadi muzakki. Bentuk filantropi Islam yang lain adalah wakaf.

Filantropi Islam berupa wakaf uang memiliki potensi besar dalam investasi keagamaan, pendidikan, dan pelayanan sosial di Indonesia (Hasan, 2010; Utami \& Ismail, 2014). Pengelolaan wakaf produktif oleh sumber daya manusia yang terampil dan profesional bisa meningkatkan produktivitas dan pengembangan wakaf sehingga kontribusi dalam bidang ekonomi, kesehatan, dan bantuan sosial menjadi optimal (Sa'adah \& Wahyudi, 2017). Selain itu, keberadaan wakaf melalui usaha mikro kecil dan menengah (UMKM) bisa menjadi kekuatan pengentasan kemiskinan, penciptaan lapangan kerja, dan peningkatan pendapatan keluarga (Cantika, 2015).

Perkembangan kebutuhan dana dari wakaf saat ini sangat besar. Dana wakaf bisa lebih produktif jika diinvestasikan untuk fasilitas publik dan semi publik semi privat (mixed public goods). Benda publik adalah fasilitas umum milik negara yang bisa dimanfaatkan semua orang tanpa membayar. Mixed public goods adalah fasilitas umum yang kepemilikannya sebagian oleh sektor swasta, sehingga masyarakat harus membayar ketika memanfaatkan fasilitas umum tersebut (Robbins, 2005). Legalisasi praktik wakaf tunai di Malaysia setelah keluarnya fatwa dari National Council of Religious Affairs Malaysia pada April 2007 di Kuala Trengganu (Rahman, 2018). Di Indonesia, praktik wakaf tunai sebagai investasi diperbolehkan MUI pada tahun 2002, namun baru diundangkan pada tahun 2004.

Praktik wakaf tunai di Bangladesh lebih mirip sebagai deposito wakaf yang bisa dimiliki semua masyarakat termasuk masyarakat kurang mampu. Hal ini disebabkan karena nilai deposit wakaf yang diterbitkan bank relatif kecil, yaitu US\$21. Hal ini merupakan kemajuan praktik wakaf di negara ini, yang sebelumnya hanya orang-orang kaya yang bisa berwakaf, saat ini semua masyarakat bisa ikut berwakaf (Çizakça, 2011). Dengan meningkatnya partisipasi masyarakat dalam program wakaf ini diharapkan akan bisa membantu pemerintah dalam menyediakan fasilitas-fasilitas publik yang dibutuhkan masyarakat. Dengan tersedianya berbagai fasilitas publik ini diharapkan bisa meningkatkan kualitas kehidupan masyarakat yang pada akhirnya bisa meningkatkan produktivitas dan ekonomi masyarakat. 
Corporate Social Responsibility (CSR) adalah bentuk tanggung jawab sosial suatu perusahaaan dalam mengembangkan kehidupan sosial masyarakat agar lebih baik (Yusuf, 2017). Keterlibatan perusahan melalui CSR saat ini merupakan keharusan untuk eksistensi perusahaan itu sendiri. Hal ini karena melalui CSR, secara tidak langsung perusahaan akan mendapatkan nilai lebih berupa kepercayaan publik. Ketika publik sudah percaya pada suatu perusahaan, perkenalan dan pemasaran produk perusahaan tersebut akan lebih mudah diterima masyarakat. Istilah CSR sendiri sebenarnya termasuk bentuk etika bisnis yang sesuai dengan nilai-nilai Islam, yaitu kepedulian terhadap lingkungan (Darrag, 2013). CSR di Kedah, Malaysia terlibat dalam kepedulian lingkungan, pengembangan masyarakat, pengembangan sumber daya manusia (Said et al., 2018). Praktik CSR sebagian perusahaan swasta di Malaysia dilakukan dengan membangun infrastruktur agar bisa memberikan kontribusi yang lebih efektif pada sektor sosial (Hasan et al, 2009). Manfaat CSR di Nigeria juga bisa mengurangi dampak kemiskinan berupa pengangguran, buta huruf, penyakit kronis, kekurangan pangan, perang antar kelompok, dan perlawanan kelompok-kelompok militan (Raimi et al., 2010).

\section{SIMPULAN}

1 Pembahasan seputar isu zakat dan filantropi Islam sudah banyak dilakukan oleh para akademisi maupun praktisi dalam bidang ini.

2 Fokus diskusi seputar zakat paling banyak adalah tentang manajemen zakat yang meliputi pengumpulan, pengaturan, dan pendistribusian zakat. Hal ini disebabkan karena masalah umum yang sering dijumpai dalam masyarakat adalah kurangnya kepercayaan masyarakat terhadap tata cara pengelolaan zakat, baik oleh swasta maupun oleh pemerintah.

3 Zakat dan filantropi Islam bisa dijadikan solusi untuk meningkatkan kesejahteraan masyarakat miskin dan mengurangi kesenjangan sosial.

4 Pentingnya meningkatkan pengetahuan yang komprehensif tentang zakat dan filantropi Islam lainnya bagi umat Islam sehingga bisa meningkatkan kesadaran membayar zakat dan filantropi Islam lainnya.

5 Dibutuhkan sosialisasi yang sungguh-sungguh kepada masyarakat oleh semua pihak, baik pemerintah maupun swasta untuk meningkatkan pemahaman tentang zakat dan kesadaran membayar zakat.

6 Diperlukan kerja sama antara peneliti agar bisa dicari penyebab kurangnya kesadaran membayar zakat muzakki sehingga ditemukan solusi yang tepat.

\section{DAFTAR PUSTAKA}

Adnan, M.A. \& Ajija, S.R. (2015). The effectiveness of baitul maal wat tamwil in reducing poverty: The case of Indonesian Islamic microfinance institution. Humanomics, 31(2), 160-182.

Al-Qohthani, S.I.A.I.W. (1426H). Shadaqah at-tathawu' fïlistāmi mafhūmu, wafadhāilu, wa adābu waanwā'u fì dhüilkitābi wassunnat. Riyadh (SA).

Alam, N. (2010). Islamic venture philanthropy: A tool for sustainable community development. Social Science Research Network.

Andreoni, J. (2001). Economics of philanthrophy. International of Encyclopedia of the Social \& Behaviour Sciences.

Anshori (2018). Studi ayat-ayat zakat sebagai instrumen ekonomi Islam dalam tafsir Al-Misbah. Misykat al-Anwar, 29(1), 498-511.

As-Syaukani, M. (1961). Nailul Authar Cet. 1. Mesir, Syirkah Maktabah al-Baby al-Halaby wa Auladuhu.

Ash-Shalabi (2014). Umar bin Abdul Aziz Khalifah Pembaharu dari Bani Umayyah. Jakarta (ID), Pustaka al-Kautsar.

Az-Zuhaili, W. (1985). Fiqh Islam Wa 'Adilatuhu. Damaskus (SY), Dar al-Fikr.

Aziz, A.D. (1997). Ensiklopedi Hukum Islam. Jakarta (ID), PT. Ichtiar.

Bhinadi, A. (2017). Penanggulangan kemiskinan dan pemberdayaan masyarakat. Deepublish. 
Cantika, S.B. (2015). Optimalisasi peran wakaf dalam usaha mikro, kecil, dan menengah (UMKM). Journal of Innovation in Business and Economics, 6(1), 1-16.

[CERPhi] Centre d'Etude et de Recherche sur la Philanthropie (2015). An Overview of Philanthropy in Europe. Perancis.

Chapra, M.U. (1992). Islam and the Economic Challenge. Riyadh (SA), International Islamic Publishing House (IIPH).

Çizakça, M. (2011). Islamic Capitalism and Finance: Origins, Evolution, and The Future. United Kingdom, Edward Elgar Publishing.

Darrag, M. \& Bassiouny, N. (2013). An introspect into the Islamic roots of CSR in the Middle East: The case of salova group in Egypt. Social Responsibility Journal, 9(3), 362-378.

[Departemen Agama] (2014). Al-Quran Terjemah dan Tajwid. Jawa Barat (ID), Sygma.

Fauzia, A. (2017). Islamic philanthropy in Indonesia: Modernization, Islamization, and social justice. Austrian Journal of South-East Asian Studies, 10(2), 223-236.

Hasan, A. \& Latiff H.S.B.A. (2009). Corporate social responsibility of Islamic financial institutions and businesses: Optimizing charity value. Humanomics, 25(3), 177-188.

Hasan, S. (2010). Wakaf uang dan implementasinya di Indonesia. Journal de Jure, 2(2).

Hasan, Z. (2014). In search of the perceptions of the Shari'ah scholars on Shari'ah governance system. International Journal of Islamic and Middle Eastern Finance and Management, 7(1), 22-36.

Hassan, H. (2005). Ensiklopedi Islam Jilid 3. Jakarta (ID), PT Ichtiar Baru Van Hoeve.

Beik, I.S. \& Arsyianti, L.D. (2016). Measuring zakat impact on poverty and welfare using CIBEST Model. Journal of Islamic Monetary Economics and Finance, 1(2), 141-160.

Ismail, A. G. (2014). Between Free Market and State Capitalism: How Islamic Economics System Shape the Future Global Economy?. Islam: Global Issues, Challenges, and Perspectives of the 21st Century, edited by Doreen Peters, 35-58.

Kasri, R.A. (2013). Giving behaviors in Indonesia: Motives and marketing implications for Islamic charities. Journal of Islamic Marketing, 4(3), 306-324.

Mehmet, O. (1997). Al-Ghazzali on social justice: Guidelines for a new world order from an early medieval scholar. International Journal of Social Economics, 24(11), 1203-1218.

Rahman, A.A. (2018). New developments in Islamic economics: Examples from Southeast Asia. Emerald Group Publishing.

Raimi, L., Bello, M.A., \& Mobolaji, H. (2010). Faith-based model as a policy response to the actualisation of the millennium development goals in Nigeria. Humanomics, 26(2), 124-138.

Robbins, D. (2005). Handbook of Public Sector Economics (Public Administration and Public Policy). Routledge.

Roelofs, J. (2007). Foundations and collaboration. Critical Sociology, 33(3), 479-504.

Roshima,S., Samad, K.A., Sidek, N.Z.M., Ilias, N.F., \& Omar N. (2018). Corporate social responsibility disclosure index of Malaysian Shariah - compliant companies. International Journal of Ethics and Systems, 34(1), 55-69.

Sa'adah, N. \& Wahyudi, F. (2016). Manajemen wakaf produktif: Studi analisis pada baitul mal di Kabupaten Kudus. Equilibrium: Jurnal Ekonomi Syari'ah, 4(2), 334-352.

Utami, A.F. \& Ismail, M. (2014). Implementasi pengelolaan wakaf tunai (studi pada Baitul Maal Hidayatullah \& Yayasan Dana Sosial Al-Falah). Jurnal Ilmiah Mahasiswa FEB, 3(1).

Yusuf, M.Y. (2014). Pola distribusi zakat produktif: Pendekatan maqasid syari'ah dan konsep CSR. Media Syari'ah, 16(1), 207-230.

Yusuf, M.B.O. \& Derus, A.M. (2013). Measurement model of corporate zakat collection in Malaysia: A test of diffusion of innovation theory. Humanomics, 28(1), 61-74.

\section{Lampiran}

Artikel Manajemen Zakat:

1 Wahab, N.A. \& Rahman, A.R.A.R. (2011). A framework to analyse the efficiency and governance of zakat institutions. Journal of Islamic Accounting and Business Research, 2(1), 43-62. 
2 Azrai Azaimi Ambrose, A.H., Gulam Hassan, M.A., \& Hanafi, H. (2018). A proposed model for waqf financing public goods and mixed public goods in Malaysia. International Journal of Islamic and Middle Eastern Finance and Management.

3 Yaacob, H., Petra, S., Sumardi, A., \& Nahar, H.S. (2015). Accountability through accounting and reporting lenses: Lessons from an awqaf institution in a Southeast Asia country. Humanomics, 31(3), 299-313.

4 Adnan, M.A. \& Bakar, N.B.A. (2009). Accounting treatment for corporate zakat: A critical review. International Journal of Islamic and Middle Eastern Finance and Management, 2(1), 32-45.

5 Muhamat, A.A., Jaafar, N., Rosly, H.E., \& Manan, H.A. (2013). An appraisal on the business success of entrepreneurial asnaf: An empirical study on the state zakat organization (the Selangor Zakat Board or Lembaga Zakat Selangor) in Malaysia. Journal of Financial Reporting and Accounting, 11(1), 51-63.

6 Shaikh, S.A., Ismail, A.G. \& Shafiai, M.H.M. (2017). Application of waqf for social and development finance. ISRA International Journal of Islamic Finance, 9(1), 5-14.

7 Djaghballou, C.E., Djaghballou, M., Larbani, M., \& Mohamad, A. (2018). Efficiency and productivity performance of zakat funds in Algeria. International Journal of Islamic and Middle Eastern Finance and Management.

8 Kasri, R.A. (2013). Giving behaviors in Indonesia: Motives and marketing implications for Islamic charities. Journal of Islamic Marketing, 4(3), 306-324.

9 Haneef, M.A., Pramanik, A.H., Mohammed, M.O., Amin, M.F., \& Muhammad, A.D. (2015). Integration of waqf-Islamic microfinance model for poverty reduction: The case of Bangladesh. International Journal of Islamic and Middle Eastern Finance and Management, 8(2), 246-270.

10 Hassan, A. (2016). Islamic ethical responsibilities for business and sustainable development. Humanomics, 32(1), 80-94.

11 Wulandari, P. \& Kassim, S. (2016). Issues and challenges in financing the poor: Case of Baitul Maal Wa Tamwil in Indonesia. International Journal of Bank Marketing, 34(2), 216234.

12 Basir, S.A., Azmi, I.A.G., Ismail, S.H.S., Ibrahim, P., \& Mohamed, H.A. (2017). Malaysian Islamic quality management system MS1900: An implementation steps at Malacca Zakat Center. Humanomics, 33(2), 239-254.

13 Aydin, N. (2014). Pareto efficiency in individualistic vs. altruistic society. Humanomics, 30(4), 304-324.

14 Johnsen, S. (2017). Social enterprise in the United Arab Emirates. Social Enterprise Journal 13, 392-409.

15 Lukman, B. \& Elatrash, S.R.J. (2017). The goods and services tax (GST) on takāful products: A critical Sharī'ah appraisal. ISRA International Journal of Islamic Finance, 9(2), 205-209.

16 Mikail, S.A., Ahmad, M.A.J., \& Adekunle, S.S. (2017). Utilisation of zakāh and waqf fund in micro-takāful models in Malaysia: An exploratory study. ISRA International Journal of Islamic Finance, 9(1), 100-105.

Artikel CSR:

1 Darrag, M. \& E-Bassiouny, N. (2013). An introspect into the Islamic roots of CSR in the Middle East: The case of Savola Group in Egypt. Social Responsibility Journal, 9(3), 362378.

2 Said, R., Samad, K.A., Sidek, N.Z.M., Ilias, N.F., \& Omar, N. (2018). Corporate social responsibility disclosure index of Malaysian Shariah-compliant companies. International Journal of Ethics and Systems, 34(1), 55-69.

3 Hassan, A. \& Salma, H. (2009). Corporate social responsibility of Islamic financial institutions and businesses: Optimizing charity value. Humanomics, 25(3), 177-188.

4 Raimi, L., Patel, A., \& Adelopo, I. (2014). Corporate social responsibility, waqf system, and zakat system as faith-based model for poverty reduction. World Journal of Entrepreneurship, Management and Sustainable Development, 10(3), 228-242. 
5 Rashid, M., Abdeljawad, I., Ngalim, S.M., \& Hassan, M.K. (2013). Customer-centric corporate social responsibility: A framework for Islamic banks on ethical efficiency. Management Research Review, 36(4), 359-378.

6 Farook, S., Hassan, M.K., \& Lanis, R. (2011). Determinants of corporate social responsibility disclosure: The case of Islamic banks. Journal of Islamic Accounting and Business Research, 2(2), 114-141.

7 Hassan, A. \& Harahap, S.S. (2010). Exploring corporate social responsibility disclosure: The case of Islamic banks. International Journal of Islamic and Middle Eastern Finance and Management, 3(3), 203-227.

Artikel Religion

1 Nahar, H.S., \& Yaacob, H. (2011). Accountability in the sacred context: The case of management, accounting and reporting of a Malaysian cash awqaf institution. Journal of Islamic accounting and business research, 2(2), 87-113.

Artikel Distribsi:

1 Shaikh, S.A., Ismail, M.A., Ismail, A.G., Shahimi, S., \& Shafiai, M.H.M. (2017). Towards an integrative framework for understanding Muslim consumption behaviour. Humanomics, 33(2), 133-149.

Artikel Filantropi:

1 Haniffa, R. \& Hudaib, M. (2012). Spotlight on the infaq sector. Journal of Islamic Accounting and Business Research, 3(1).

2 Sadr, S.K. (2017). The optimum size of rotating qarḍ hasan savings and credit associations. ISRA International Journal of Islamic Finance, 9(1), 15-26.

3 Kachkar, O.A. (2017). Towards the establishment of cash waqf microfinance fund for refugees. ISRA International Journal of Islamic Finance, 9(1), 81-86.

4 Muhammad, I.N. (2010). Scholars, merchants and civil society: Imperative for waqf-based participatory poverty alleviation initiatives in Kano, Nigeria. Humanomics, 26(2), 139-157.

5 Choudhury, M.A., Hossain, M.S., \& Solaiman, M. (2008). A well-being model of small-scale microenterprise development to alleviate poverty: A case study of Bangladesh village. International journal of sociology and Social policy, 28(11/12), 485-501.

Artikel Zakat:

1 Saad, R.A.J. \& Haniffa, R. (2014). Determinants of zakah (Islamic tax) compliance behavior. Journal of Islamic Accounting and Business Research, 5(2), 182-193.

2 Samad, A. \& Glenn, L.M. (2010). Development of Zakah and Zakah coverage in monotheistic faiths. International Journal of Social Economics, 37(4), 302-315.

3 Obaidullah, M. (2016). Revisiting estimation methods of business zakat and related tax incentives. Journal of Islamic Accounting and Business Research, 7(4), 349-364.

Artikel Poverty:

1 Raimi, L., Bello, M.A., \& Mobolaji, H. (2010). Faith-based model as a policy response to the actualisation of the millennium development goals in Nigeria. Humanomics, 26(2), 124-138.

2 Hassan, A. (2014). The challenge in poverty alleviation: Role of Islamic microfinance and social capital. Humanomics, 30(1), 76-90.

3 Adnan, M.A. \& Ajija, S.R. (2015). The effectiveness of Baitul Maal wat Tamwil in reducing poverty: The case of Indonesian Islamic Microfinance Institution. Humanomics, 31(2), 160182.

Artikel Collection:

1 Yusuf, M.B.O. \& Derus, A.M. (2013). Measurement model of corporate zakat collection in Malaysia: A test of diffusion of innovation theory. Humanomics, 29(1), 61-74. 